\title{
Highly Sensitive Tri-Path Photonic Crystal Fiber Plasmonic Sensor Based on Hybrid Layer of Gold / Platinum Diselenide
}

\section{Vijayalakshmi Dhinakaran ( $\square$ vijayalakshmid17@gmail.com )}

SRMIST: SRM Institute of Science and Technology https://orcid.org/0000-0001-5298-0475

\section{C.T. Manimegalai}

SRMIST: SRM Institute of Science and Technology

\section{Natesan Ayyanar}

Ton Duc Thang University

\section{Truong Khang Nguyen}

Ton Duc Thang University

\section{K. Kalimuthu}

SRM Institute of Science and Technology

\section{Research Article}

Keywords: Surface Plasmon Resonance, Tri-path photonic crystal fiber, Coupling effect, Platinum Diselenide, Finite element method

Posted Date: April 16th, 2021

DOl: https://doi.org/10.21203/rs.3.rs-419957/v1

License: (c) (i) This work is licensed under a Creative Commons Attribution 4.0 International License.

Read Full License

Version of Record: A version of this preprint was published at Optical and Quantum Electronics on August 6th, 2021. See the published version at https://doi.org/10.1007/s11082-021-03092-7. 


\section{Abstract}

Platinum Diselenide, PtSe2 is becoming highly trending owing to its fascinating optoelectronic, thermoelectric and semiconductor properties. They are non-toxic, chemically inert and allow high biomolecule absorption which makes them highly applicable in sensors to boost the sensing performance. Here, we propose Surface Plasmon Resonance (SPR) based Photonic Crystal Fiber (PCF) sensor for enhanced refractive index sensing at mid infrared wavelengths. In order to achieve this, tri-path PCF coated with hybrid layer of gold/PtSe2 which allows light to travel freely through the cladding and interact with the plasmonic material to create strong coupling effect. Finite Element Method is used for numerical examination and investigation of the sensing performance for the designed tri-path sensor. The optimized proposed sensor exhibits maximum wavelength sensitivity of $42,000 \mathrm{~nm} / \mathrm{RIU}$ and maximum wavelength resolution of $2.4 \times 10^{-6}$ within the analyte range from 1.33 to 1.38 , which almost covers the unknown analytes of chemical, bio and gas. Further, we achieve very low loss and unique design to accomplish high sensitivity which makes it applicable to be a future candidate in various sensing applications.

\section{Introduction}

Photonic Crystal Fiber (PCF) is highly trending in photonics which is a single material providing a platform for sensing (Wei et al. 2013). They offer high design flexibility which creates high birefringence, high confinement field, endlessly single material, tunable dispersion, compact sensing and many more. When this PCF material is combined with plasmonic science, high sensitivity results will be achieved which paves way for being a potential future candidate in various fields (Vigneswaran et al., 2018). Surface Plasmon Resonance (SPR) is a promising sensing technique that detects the minimum variation in refractive index $(\mathrm{RI})$ when there is an interaction with the metal film. They expose high sensitivity results which makes it trending and highly applicable in various sensing fields. As SPR is label free and real time detection process which produces high sensitivity, intensive research curiosity for the scientists has been highly stimulated for making more advancements in the sensors (Rahman et al., 2020). They are growing tremendously from the scientific region as there are extensive applications that also include temperature monitoring (Luan et al. 2017), multi analyte sensing (Otupiri et al., 2015), biosensing (Akowuah et al., 2012), liquid sensing (Kaur et al., 2019), disease diagnosis (Jabin et al., 2019) and many more. The most popularly used plasmonic is gold as it is chemically stable, provide long resonant shift, biocompatible and is prone to oxidation (Singh et al., 2020 \& Hasan et al. 2017).

Lately, along with the plasmonics, flimsy oxide layers are added such as aluminium oxide $\left(\mathrm{Al}_{2} \mathrm{O}_{3}\right)$, indiumtin oxide (ITO), titanium dioxide $\left(\mathrm{TiO}_{2}\right)$ to elevate the sensing performance of the sensor. They assist in robust SPR effect which aid to improve the sensing range along with sensitivity for the sensor (Mahfuz et al., 2019). But these plasmonics and additional coating layers also face a drawback where they have very low biomolecule absorption capability in biosensors. To defeat this drawback, it was suggested to use biomolecule recognition elements as Transition Metal Dichalcogenide (TMDC) materials along with the 
that have intriguing features and unique structure that have made them highly attractive and significant in various industrial applications owing to its capability for biomolecule recognition and sensitivity enhancement (Wu et al., 2016). 2D materials limit the transport of heat and charge in their unique layered structure which is an exceptional property capable, making them enticing for optoelectronic and electronic applications (Gong et al., 2020). One of the leading factors for determining the properties and applications in 2D materials is the bandgap. These 2D materials have tunable finite band gap which make them to be a promising candidate in numerous applications (Zhang et al., 2020). These materials exhibit exclusive properties as large absorption of light, high charge mobility and transitional behavior which build them more appropriate for fabricating high performance electronic and optoelectronic devices (Guo et al., 2020). Graphene was the first man-made and discovered 2D nanomaterial in 2004. Due to its inter-band transition, it exposes good optical conductivity from near to mid infrared frequency, produces huge surface to volume ratio aiding high biocompatibility (Singh et al., 2020). There are many other 2D materials as $\mathrm{MoS}_{2}$ (Radisavljevic et al., 2011), $\mathrm{WO}_{3}$ (Wang et al., 2014), WS 2 (AlaguVibisha et al., 2016), $\mathrm{PtSe}_{2}$ (Xie et al., 2019), etc which are recently trending in the research field. These materials have excellent properties as optical, thermal, electronics, optoelectronics, catalytic, super conductivity and energy-storage (Zhang et al., 2020). The investigation and analysis of the 2D materials along with its properties was first initiated by coating them over the prism as sensors (Ouyang et al., 2016). In 2016, highly sensitive prism based SPR sensor was reported using 2D materials. It is heterostructured configuration where the arrangement was made as $\mathrm{MoS}_{2} /$ Aluminium/MoS $2 /$ Graphene. The sensor exposes a maximum sensitivity of $190.83 \otimes / R I U$ (Wu et al., 2016). Specifically, Platinum Diselenide $\left(\mathrm{PtSe}_{2}\right)$ is a group ten monolayer material in $1 \mathrm{~T}$ phase and it is highly preferred owing to their exclusive features (Guo et al., 2020). They resemble the structure of phosphorene and graphene and also reveals admirable thermoelectric, optoelectronic and semiconductor properties making it more unique. Owing to its robust interlayer interaction, the 2D material $\mathrm{PtSe}_{2}$ exposes high tunable bandgap. Moreover, this material is observed to have good chemical stability with also less toxic which makes it highly applicable for practical usage (Jia et al., 2020). Recently, a sensor was proposed where $\mathrm{PtSe}_{2}$ was selected to attain maximum Goos-Hanchen shift. The sensor has gold and titanium coating along with $\mathrm{PtSe}_{2}$ and three layers of graphene is added in BK7 prism. The results revealed the Goos-Hanchen shift sensitivity shows an increment four times when compared with the plain gold coating. The detection limit is very low as $5 \mathrm{x}$ $10^{-7}$ RIU which is diminished by 2 order of magnitude and sensitivity elevates by 1000 -fold when compared with plain gold coating (Guo et al., 2020). Hence, 2D material based SPR sensors are recommended for RI sensing as they exhibit highly improved sensitivity (Jia et al., 2020).

The PCF combined with SPR sensing method along with various additional coating materials were investigated extensively as it was perceived to reveal superior sensitivity for the sensors. In 2016, SPR combined with D-shape PCF was mentioned with plasmonic metal employed as gold and additional coating layer of ITO for RI ranging from 1.28 to 1.34 . The sensor gains a high sensitivity of $6000 \mathrm{~nm} / \mathrm{RIU}$ (Huang et al., 2017). In 2018, PCF combined with SPR sensor was reported with bimetallic coating of new plasmonic material as niobium nanofilm along with additional covering of flimsy $\mathrm{Al}_{2} \mathrm{O}_{3}$ for organic and 
biochemical sensing. The sensor functions for analyte RI 1.36 to 1.41 and reveals a maximum sensitivity of $8000 \mathrm{~nm} / \mathrm{RIU}$ (Hasan et al., 2018). Highly birefringent and simple design PCF-SPR was presented with gold as plasmonic and $\mathrm{TiO}_{2}$ as additional thin layer forming the bimetallic structure. The sensor operates for RI range from 1.33 to 1.38 and exposes a high sensitivity of $25,000 \mathrm{~nm} / \mathrm{RIU}$ making it highly suitable in numerous sensing applications (Islam et al., 2019). Recently, dual core PCF-SPR sensor with bimetallic coating layers of gold and $\mathrm{TiO}_{2}$ was described for numerous biochemical analytes and bio-organic molecules RI detection. The sensor functions for analyte RI range of 1.33 to 1.42 , disclosing a maximum sensitivity of $28,000 \mathrm{~nm} / \mathrm{RIU}$ (Al Mahfuz et al., 2020). But these plasmonics with additional layers have low capability of biomolecule absorption. So, 2D materials were recommended to be used as additional covering layers along with plasmonics over PCF as they are excellent in biomolecule recognition (Singh et al., 2020). The real time PCF based modal interferometer was mentioned for auditing the concentration of dissolved hydrogen in the transformer oil. The sensor was coated with $\mathrm{Pd} / \mathrm{WO}_{3}$ film over PCF by employing dip-coating technique. For the range $0-10000 \mu \mathrm{l} / \mathrm{l}$, the sensitivity acquired is $0.109 \mu \mathrm{l} / \mathrm{I}$ with response time below 33 minutes (Zhang et al., 2016). Further, D-shape PCF was described with monolayer $\mathrm{MoS}_{2}$ which was accumulated at the plane surface to boost the sensitivity of the sensor. The sensor functions for analyte RI range of 1.33 to 1.36 and attains a maximum sensitivity of $2000 \mathrm{~nm} / \mathrm{RIU}$ (Nivedha et al., 2017). In 2019, PCF sensor combined with SPR was presented where thin film of gold was employed as the plasmonic along with flimsy graphene layer for detection of RI in liquid sample. The sensor operates for analyte RI range from 1.33 to 1.38 . With the addition of graphene layer, the sensor improvises by $84.66 \%$ and reveals a maximum sensitivity of $8600 \mathrm{~nm} / \mathrm{RIU}$ (Lou et al., 2019). Lately, a Dshaped PCF-SPR sensor with coating layers of gold/MoS $2 /$ graphene was reported. The sensor was applicable for biomedical and biochemical analyte detection for the analyte RI ranging from 1.33 to 1.40 . The sensor exposes a maximum sensitivity of $14,933.34 \mathrm{~nm} / \mathrm{RIU}$ (Singh et al., 2020). The above reported papers along with additional layer covering exhibit high loss and less sensitivity. So, for the first time in this work, $2 \mathrm{D}$ material $\mathrm{PtSe}_{2}$ is integrated through plasmonics over the outer surface of PCF to upsurge the sensitivity which reveals the novelty for this work along with which the designed tri-path sensor exposes a low loss.

We present a tri-path PCF sensor which is integrated with $\mathrm{PtSe}_{2}$ through plasmonic gold to achieve high sensitivity for the designed sensor. The tri-path structure is introduced for the evanescent field to move freely through the cladding and interact with the metal region to create strong plasmonic coupling effect. This assists in reaching enhanced sensitivity for the designed sensor. External sensing is approached which removes the fabrication complexities for the sensor. Gold along with $\mathrm{PtSe}_{2}$ is employed as it reveals excellent sensitivity and unique properties which make the sensor a potential future candidate in many fields. The next, Sect. 2 discusses about the design and its novelty. Further, in Sect. 3 , the coupling characteristics and results will be mentioned. Finally, in Sect. 4, the optimizations done for the geometrical parameters will be elaborately discussed.

\section{Structural Desian}


The schematic view of designed tri-path PCF sensor is displayed in Fig. 1. There are two air hole rings present which are organized in hexagonal lattice. The center air hole along with three air holes from first ring are removed. Further, three air holes from second ring are also scaled down. This arrangement is done for light to travel in an effective path. This arrangement leads to the formation of tripath structure which paves way for the light to travel easily. The guided evanescent field from core move freely through the cladding and strikes the metal region, creating strong coupling effect. This boosts the sensing performance of the designed tri-path PCF sensor making the sensor to attain high sensitivity. The diameter of big sized air hole, $d$ is $1.4 \mu \mathrm{m}$ and the diameter of scaled down air hole is symbolized as $d_{s}$ which is $0.2 \mu \mathrm{m}$. Pitch is represented as $\Lambda$ which is the distance from center of one air hole to another.

Silica is used as the background element for the designed sensor whose RI is dependent on wavelength and expressed using Sellmeier equation (Ayyanar et al., 2018);

$$
n^{2}=1+\sum_{i=1}^{3} \frac{N_{i} \lambda^{2}}{\lambda^{2}-\lambda_{i}^{2}}(1)
$$

where refractive index of silica is denoted by $n, \lambda_{i}$ and $N_{i}$ are the appropriate constants, where $\lambda_{1}=$ $0.0684043, \lambda_{2}=0.1162414, \lambda_{3}=9.8961611$ and $N_{1}=0.6961663, N_{2}=0.4079426, N_{3}=0.8974794$. The plasmonic material preferred for the designed sensor is gold whose thickness is denoted as $\mathrm{t}_{\mathrm{g}}=40 \mathrm{~nm}$. Drude Lorentz model is used to obtain the dielectric gold constant which is expressed as (Vial et al., 2005);

$$
\epsilon_{\text {gold }}(\omega)=\epsilon_{\infty}-\frac{\omega_{D}^{2}}{\omega\left(\omega+i \gamma_{D}\right)}-\frac{\Delta \epsilon \cdot \Omega_{L}^{2}}{\left(\omega^{2}-\Omega_{L}^{2}\right)+i \Gamma_{L} \omega}
$$

where, the permittivity of gold is $\varepsilon_{\text {gold }}$, angular frequency is $\omega=6.283 \mathrm{c} / \lambda, \varepsilon_{\infty}=5.9673$ is high frequency permittivity, and $\Delta \varepsilon=1.09$ is the weighing factor. The damping frequency and plasma is denoted as $Y_{D}=$ $2 \pi * 15.92 \mathrm{THz}$ and $\omega_{D}=2 \pi * 2113.6 \mathrm{THz}$ respectively. Moreover, oscillator strength is $\Omega_{\mathrm{L}}=2 \pi * 650.07 \mathrm{THz}$ and the spectral width is $\Gamma_{L}=2 \pi^{*} 104.86 \mathrm{THz}$ of the Lorentz oscillators.

Gold is applied with the help of various methods as thermal evaporation (Barnes et al., 2000), wet chemistry deposition (Sioss et al., 2005) and radio sputtering technique (Armelao et al., 2005). These methods result in extreme surface roughness which diminishes the usage of these coating methods. To solve the issue of rough uneven surface, another coating method known as chemical vapour deposition (CVD) (Sazio et al., 2006) is employed which offers minimum roughness along with even coating on the surface. Further, $\mathrm{PtSe}_{2}$ was glazed over the plasmonic gold metal whose thickness is taken to be $4 \mathrm{~nm}$. The RI for PtSe ${ }_{2}$ is obtained from the cited paper (Guo et al., 2020) which involves both real and 
approaching external sensing technique which removes the fabrication complexities. Perfectly Matched Layer (PML) along with scattering boundary conditions are added which protects from removing the radiant energy from fiber axis. Further, numerical study is done through Finite Element Method (FEM) which is associated with COMSOL Multiphysics software and results are discussed in upcoming sections.

\section{Results And Analysis}

The proposed model sensing mechanism is based on the coupled mode theory (Ayyanar et al., 2018) which takes place amongst the evanescent field from the core mode that interacts with plasmonic mode at gold/Ptse ${ }_{2}$ layer to produce robust coupling effect. Figure 2 illustrates the electric field distribution where figure 2(a) as well as (b) displays the field distribution for fundamental core mode and plasmonic mode. Figure 2(c) reveals the coupling effect for the analyte 1.36. The designed tri-path sensor functions for the sensing range from 1.33 to 1.38 where the shift in wavelength and variation in peak intensity is observed when the analyte RI is varied.

Figure 3 illustrates the dispersion relation and loss spectrum of core mode and plasmonic mode. When the interaction takes place amidst the fundamental core and SPP mode, phase matching condition occurs at a specific wavelength which is termed as resonant wavelength. The confinement loss is calculated by (Xie et al., 2019);

$$
\alpha_{L}\left(\frac{d B}{c m}\right)=8.686 \times k_{0} \times \operatorname{Im}\left(n_{\text {eff }}\right) \times 10^{4}
$$

where, $\lambda$ indicates the input wavelength in microns, the effective RI of the imaginary part is signified by $\mathrm{Im}$ $\left(n_{\text {eff }}\right)$ and $\mathrm{k}_{0}=2 \pi / \lambda$ denotes free space number. Maximum loss peak is attained in this resonant wavelength and while shift occurs in this wavelength towards shorter or longer wavelength, the anonymous sample can be detected. By the collision within core and SPP mode for the designed tri-path sensor, the maximum peak reached is $14.10 \mathrm{~dB} / \mathrm{cm}$ at the wavelength $0.84 \mu \mathrm{m}$ for the analyte 1.36 .

Figure 4 depicts the loss spectrum for analyte RI varied from 1.33 to 1.38. The peak loss attained for the designed tri-path sensor with gold/PtSe ${ }_{2}$ layer coating is $1.36 \mathrm{~dB} / \mathrm{cm}, 2.14 \mathrm{~dB} / \mathrm{cm}, 2.76 \mathrm{~dB} / \mathrm{cm}, 2.97$ $\mathrm{dB} / \mathrm{cm}, 4.55 \mathrm{~dB} / \mathrm{cm}$ and $12.82 \mathrm{~dB} / \mathrm{cm}$ at their corresponding resonance wavelength $0.72 \mu \mathrm{m}, 0.74 \mu \mathrm{m}$, $0.79 \mu \mathrm{m}, 0.85 \mu \mathrm{m}, 0.96 \mu \mathrm{m}$ and $1.38 \mu \mathrm{m}$ respectively. This shows that the loss attained for the designed sensor is also very low making it more efficient and practical. Figure 5 portrays the polynomial fit characteristic analysis for analyte RI altered from 1.33 to 1.38 for the designed tri-path sensor with coating of gold/ $\mathrm{PtSe}_{2}$. For this range, the degree relation amidst the resonant wavelength and analyte RI is estimated by $R^{2}$. The $R^{2}$ value acquired for the designed tri-path sensor is 0.91438 . High polynomial regression charecteristic is revealed which proves the quality of the designed tri-path sensor that can be employed for precise analyte RI identification. Wavelength ssensitivity is significant parameter that is 
employed to calculate the sensing performance for the designed tri-path sensor. The wavelength sensitivity is estimated by (Chakma et al., 2018);

$$
\mathrm{S}_{\lambda}\left(\frac{\mathrm{nm}}{\mathrm{RIU}}\right)=\frac{\Delta \lambda_{\text {peak }}}{\Delta \mathrm{n}_{a}}
$$

Where $\Delta \mathrm{n}_{\mathrm{a}}$ is change in RI of analyte and $\Delta \lambda_{\text {peak }}$ is the discrepancy in shift of wavelength peak. The wavelength sensitivity calculated and obtained for the designed tri-path sensor with gold/PtSe ${ }_{2}$ coating is $2000 \mathrm{~nm} /$ RIU, $5000 \mathrm{~nm} / \mathrm{RIU}, 6000 \mathrm{~nm} / \mathrm{RIU}, 11,000 \mathrm{~nm} / \mathrm{RIU}$ and 42,000 nm/RIU for its corresponding RI analyte $1.33,1.34,1.35,1.36$ and 1.37. Further, resolution is another important parameter that is needed to measure the sensing performance of the designed sensor. It is the efficiency to sense slight alterations in RI of analyte and is realized by (Haider et al., 2018);

$$
\mathrm{R}(\mathrm{RIU})=\frac{\Delta \mathrm{n}_{\mathrm{a}} \Delta \lambda_{\min }}{\Delta \lambda_{\text {peak }}}
$$

where, $\Delta \lambda_{\min }$ is $0.1 \mathrm{~nm}$ which denotes the minimum spectral resolution which, $\Delta \lambda_{\text {peak }}$ denotes the difference in wavelength amongst the loss peak shift and $\Delta n_{a}$ is 0.01 which denotes the analyte RI alteration. From simulation and result analysis, we observe that the maximum sensitivity attained for designed tri-path sensor is $42,000 \mathrm{~nm} / \mathrm{RIU}$ along with maximum wavelength resolution of $2.4 \times 10^{-6} \mathrm{RIU}$ for the analyte 1.37. Table 1 gives the synopsis of sensing performance of designed tripath sensor for the $\mathrm{RI}$ of analyte altered from 1.33 to 1.38 .

Table 1: Sensing performance synopsis of designed tri-path sensor with gold/Ptse2 for analyte RI altered from 1.33 to1.38.

\begin{tabular}{|llllll|}
\hline $\begin{array}{l}\text { Analyte } \\
\text { RI }\end{array}$ & $\begin{array}{l}\text { Resonance Peak } \\
\text { Wavelength }(\mu \mathrm{m})\end{array}$ & $\begin{array}{l}\text { Peak } \\
\text { loss } \\
(\mathbf{d B} / \mathrm{cm})\end{array}$ & $\begin{array}{l}\text { Peak } \\
\text { wavelength } \\
\text { shift }(\mu \mathrm{m})\end{array}$ & $\begin{array}{l}\text { Wavelength } \\
\text { Sensitivity } \\
(\mathrm{nm} / \mathrm{RIU})\end{array}$ & $\begin{array}{l}\text { Wavelength } \\
\text { Resolution } \\
(\mathrm{RIU})\end{array}$ \\
\hline 1.33 & 0.72 & 1.36 & 0.02 & 2000 & $5.0 \mathrm{E}-05$ \\
\hline 1.34 & 0.74 & 2.14 & 0.05 & 5000 & $2.0 \mathrm{E}-05$ \\
\hline 1.35 & 0.79 & 2.76 & 0.06 & 6000 & $1.7 \mathrm{E}-05$ \\
\hline 1.36 & 0.85 & 2.97 & 0.11 & 11000 & $9.1 \mathrm{E}-06$ \\
\hline 1.37 & 0.96 & 4.55 & 0.42 & 42000 & $2.4 \mathrm{E}-06$ \\
\hline 1.38 & 1.38 & 15.82 & - & - & - \\
\hline
\end{tabular}

Further optimizations and its analysis are done with coating of gold/PtSe 2 layer where the geometrical parameters are scrutinized and adjusted to attain high sensitivity for the designed tri-path sensor. The scrutiny of optimization and its results are discussed elaborately below. Primarily, the values of 
$1.4 \mu \mathrm{m}$, gold layer thickness of gold coating $\left(\mathrm{t}_{\mathrm{g}}\right)$ as $40 \mathrm{~nm}$ and $\mathrm{PtSe}_{2}$ thickness as $4 \mathrm{~nm}$. These parameters are scrutinized and investigated to achieve maximum sensitivity for the designed tri-path sensor.

The scaled down air hole diameter is optimized as $0.2 \mu \mathrm{m}, 0.3 \mu \mathrm{m}$ and $0.4 \mu \mathrm{m}$ for analyte RI 1.36 and 1.37 respectively. The effect of this alteration is illustrated in Figure 6. The obtained loss peak for analyte 1.36 is $37.68 \mathrm{~dB} / \mathrm{cm}, 14.10 \mathrm{~dB} / \mathrm{cm}$ and $6.24 \mathrm{~dB} / \mathrm{cm}$ and for analyte 1.37 it is attained as $50.47 \mathrm{~dB} / \mathrm{cm}$, $20.54 \mathrm{~dB} / \mathrm{cm}$ and $9.27 \mathrm{~dB} / \mathrm{cm}$. It is evident from this investigation that the loss spectrum for analyte 1.36 transpires at $0.84 \mu \mathrm{m}$ and for analyte 1.37 it occurs at $0.93 \mu \mathrm{m}$. It is noticed that the loss occurs at the same resonant wavelength for the RI 1.36 and 1.37 as mentioned above where there is no wavelength shift revealed for these alterations made. The main purpose of the scaled down air hole is to create path for the light to interact with the plasmonic region and elevate the coupling effect. So, the size of the scaled down air hole cannot be incremented above certain value as it will diminish the space for the light to pass through which will weaken the coupling effect and reduce the sensing performance of the designed sensor. Thus, we choose optimum value of $0.4 \mu \mathrm{m}$ as the scaled down air hole diameter which is low peak loss for the designed tri-path sensor.

Next, the ratio amongst the diameter of big air hole and pitch $(\mathrm{d} / \Lambda)$, was modified and analyzed for analyte RI 1.36 and 1.37 as $0.8 \mu \mathrm{m}, 0.85 \mu \mathrm{m}$ and $0.9 \mu \mathrm{m}$. The examinations were done for the mentioned modifications where loss peak of $5.67 \mathrm{~dB} / \mathrm{cm}, 4.97 \mathrm{~dB} / \mathrm{cm}$ and $6.24 \mathrm{~dB} / \mathrm{cm}$ was attained for the analyte RI 1.36 at wavelength of $0.76 \mu \mathrm{m}, 0.79 \mu \mathrm{m}$ and $0.84 \mu \mathrm{m}$. Similarly, for analyte 1.37 , the loss peak attained is $8.22 \mathrm{~dB} / \mathrm{cm}, 7.38 \mathrm{~dB} / \mathrm{cm}$ and $9.27 \mathrm{~dB} / \mathrm{cm}$ at wavelength of about $0.81 \mu \mathrm{m}, 0.85 \mu \mathrm{m}$ and $0.93 \mu \mathrm{m}$ respectively. The modification in $d / \Lambda$ is depicted in Figure 7 . From this scrutiny, we can observe that the wavelength swings towards longer wavelength which is termed as red shift. The shift takes place from $0.76 \mu \mathrm{m}$ to $0.84 \mu \mathrm{m}$ and $0.81 \mu \mathrm{m}$ to $0.93 \mu \mathrm{m}$ for analyte RI 1.36 and 1.37 respectively. The obtained wavelength sensitvity is $5000 \mathrm{~nm} /$ RIU for $0.8 \mu \mathrm{m}, 6000 \mathrm{~nm} / \mathrm{RIU}$ for $0.85 \mu \mathrm{m}$ and $9000 \mathrm{~nm} / \mathrm{RIU}$ for $0.9 \mu \mathrm{m}$. We can conclude from the results that the highest wavelength sensitivity is reached for $0.9 \mu \mathrm{m}$ as 9000 $\mathrm{nm} / \mathrm{RIU}$ which is decided to be the optimum value. Further modifications and elevations cannot be done for $d / \Lambda$ as the designed tri-path sensor does not allow design flexibilty above this. So, from scrutiny, we opt $0.9 \mu \mathrm{m}$ as the ratio amongst diameter of big air hole and pitch for further study.

The further study analysis is done for changes in thickness of gold layer $\mathrm{t}_{\mathrm{g}}$. For analyte RI 1.36 and 1.37, the changes done in $\mathrm{t}_{\mathrm{g}}$ is $30 \mathrm{~nm}, 40 \mathrm{~nm}$ and $50 \mathrm{~nm}$. The results are displayed in Figure 8 . It is noticed that the loss peak obtained is $10.91 \mathrm{~dB} / \mathrm{cm}, 6.24 \mathrm{~dB} / \mathrm{cm}$ and $2.97 \mathrm{~dB} / \mathrm{cm}$ for analyte RI 1.36 at $0.8 \mu \mathrm{m}, 0.84$ $\mu \mathrm{m}$ and $0.85 \mu \mathrm{m}$ respectively. This shows that as thickness of gold rises, the loss decreases correspondingly. Further, for analyte 1.37 , the loss peak reached is $16.81 \mathrm{~dB} / \mathrm{cm}, 9.27 \mathrm{~dB} / \mathrm{cm}$ and 4.55 $\mathrm{dB} / \mathrm{cm}$ at $0.88 \mu \mathrm{m}, 0.93 \mu \mathrm{m}$ and $0.96 \mu \mathrm{m}$ respectively. The shift is observed to move towards larger wavelength from $0.8 \mu \mathrm{m}$ to $0.85 \mu \mathrm{m}$ and from $0.88 \mu \mathrm{m}$ to $0.96 \mu \mathrm{m}$ for analyte RI 1.36 and 1.37 respectively. This exposes that red shift takes place and loss peak correspondingly diminishes when thickness of plasmonic gold covering layer is incremented. For the changes made in $\mathrm{t}_{\mathrm{g}}$ as $30 \mathrm{~nm}, 40 \mathrm{~nm}$ Loading [MathJax]/jax/output/CommonHTML/fonts/TeX/fontdata.js /RIU, $9,000 \mathrm{~nm} / \mathrm{RIU}$ and 11,000 nm/RIU. So it is 
revealed from the investigation that highest wavelength sensitivity is gained as $11,000 \mathrm{~nm} / \mathrm{RIU}$ for $50 \mathrm{~nm}$ thickness which is preferred as the optimum value after optimization analysis and study. The thickness should be selected in right amount for efficient functioning of the sensor. If the thicknesss is too low, then the plasmonic effect will be very less which will not be applicable for coupling to transpire. Similarly, if the thickness is surged too high, then the plasmonic effect would get very robust which would weaken the coupling effect as the evanescent field decays while reaching the thick plasmonic coating and highly increment the loss. Thus, precise thickness should be opted for the designed sensor to make the sensor operate efficiently. Hence, we select $50 \mathrm{~nm}$ as thickness of gold coating for further analysis.

The final scrutinization is for the thickness of $\mathrm{PtSe}_{2}$ material. The thickness of $\mathrm{PtSe}_{2}$ is adjusted as $2 \mathrm{~nm}$, $4 \mathrm{~nm}$ and $6 \mathrm{~nm}$ for analyte RI 1.36 and 1.37 . The loss acquired is $2.66 \mathrm{~dB} / \mathrm{cm}, 2.97 \mathrm{~dB} / \mathrm{cm}$ and 3.27 $\mathrm{dB} / \mathrm{cm}$ for the analyte RI 1.36 at $0.78 \mu \mathrm{m}, 0.85 \mu \mathrm{m}$ and $1 \mu \mathrm{m}$ respectively. Similarly, at $0.82 \mu \mathrm{m}, 0.96 \mu \mathrm{m}$ and $1.06 \mu \mathrm{m}$ the loss peak attained is $4.26 \mathrm{~dB} / \mathrm{cm}, 4.55 \mathrm{~dB} / \mathrm{cm}, 4.43 \mathrm{~dB} / \mathrm{cm}$ for analyte 1.37 respectively. This is portrayed in the Figure 9. It is noticed that the wavelength swings towards larger wavelength for both RI of analyte 1.36 and 1.37 from $0.78 \mu \mathrm{m}$ to $1 \mu \mathrm{m}$ and from $0.82 \mu \mathrm{m}$ to $1.06 \mu \mathrm{m}$ respectively which depicts the red shift occurance. Further, wavelength sensitivity has been estimated for the adjustmaents made with thickness of $\mathrm{PtSe}_{2}$ material as $2 \mathrm{~nm}, 4 \mathrm{~nm}$ and $6 \mathrm{~nm}$ as $4000 \mathrm{~nm} / \mathrm{RIU}, 11,000 \mathrm{~nm} / \mathrm{RIU}$ and $6000 \mathrm{~nm} / \mathrm{RIU}$. From this we can conclude that for $4 \mathrm{~nm}$ of $\mathrm{PtSe}_{2}$ thickness, maximum sensitivity of $11,000 \mathrm{~nm} / \mathrm{RIU}$ is attained. The thickness of $2 \mathrm{D}$ material, $\mathrm{PtSe}_{2}$ is fixed to be $4 \mathrm{~nm}$ as it exposes the maximum sensitivity for the designed tri-path sensor. The other optimizations of $2 \mathrm{~nm}$ and $6 \mathrm{~nm}$ reveal a lower sensitivity when compared to $4 \mathrm{~nm}$. Hence, we decide $4 \mathrm{~nm}$ as thickness of $\mathrm{PtSe}_{2}$ material. Finally, we have completed the optimization analysis and have selected the optimized parameters as $d_{s}=0.4 \mu \mathrm{m}$, $\mathrm{d} / \Lambda=0.9 \mu \mathrm{m}, \mathrm{t}_{\mathrm{g}}=50 \mathrm{~nm}$ and Ptse $_{2}$ thickness $=4 \mathrm{~nm}$ with which the designed tri-path sensor reaches maximum sensitivity as $42,000 \mathrm{~nm} / \mathrm{RIU}$.

Moreover, we have examined the sensing performance of the designed tri-path sensor by eliminating the $\mathrm{PtSe}_{2}$ coating layer. Figure 10 portrays the loss spectrum for analyte RI varied from 1.33 to 1.38 for the designed tri-path sensor without PtSe ${ }_{2}$ coating. At wavelength $0.63 \mu \mathrm{m}, 0.64 \mu \mathrm{m}, 0.66 \mu \mathrm{m}, 0.69 \mu \mathrm{m}, 0.74$ $\mu \mathrm{m}$ and $0.84 \mu \mathrm{m}$ the loss obtained for the designed sensor when $\mathrm{PtSe}_{2}$ material is detached is 1.47 $\mathrm{dB} / \mathrm{cm}, 1.79 \mathrm{~dB} / \mathrm{cm}, 1.90 \mathrm{~dB} / \mathrm{cm}, 3.07 \mathrm{~dB} / \mathrm{cm}, 3.47 \mathrm{~dB} / \mathrm{cm}$ and $5.78 \mathrm{~dB} / \mathrm{cm}$ respectively. Figure 11 portrays the polynomial fitting analysis for analyte RI altered from 1.33 to 1.38 for the designed tri-path sensor when $\mathrm{PtSe}_{2}$ material is removed and attained $\mathrm{R}^{2}$ value is 0.98267 . The wavelength sensitivity is $1000 \mathrm{~nm} /$ RIU, $2000 \mathrm{~nm} / \mathrm{RIU}, 3000 \mathrm{~nm} / \mathrm{RIU}, 4000 \mathrm{~nm} / \mathrm{RIU}$ and 11,000 nm/RIU for analyte RI 1.33, 1.34, $1.35,1.36$ and 1.37 respectively. Through this simulation and study analysis, we can witness that the sensitivity attained for designed tri-path sensor with no $\mathrm{PtSe}_{2}$ material is $11,000 \mathrm{~nm} / \mathrm{RIU}$ with maximum wavelength resolution of $1 \times 10^{-5}$ for the analyte 1.37. Table 2 gives an overall sensing performance of designed tripath sensor when $\mathrm{PtSe}_{2}$ material is removed for the RI analyte ranging from 1.33 to 1.38 .

Table 2: Overall sensing performance of designed tri-path sensor with no $\mathrm{PtSe}_{2}$ material coating for Loading [MathJax]/jax/output/CommonHTML/fonts/TeX/fontdata.js 


\begin{tabular}{|llllll|}
\hline $\begin{array}{l}\text { Analyte } \\
\text { RI }\end{array}$ & $\begin{array}{l}\text { Resonance Peak } \\
\text { Wavelength }(\mu \mathrm{m})\end{array}$ & $\begin{array}{l}\text { Peak } \\
\text { loss } \\
(\mathbf{d B} / \mathrm{cm})\end{array}$ & $\begin{array}{l}\text { Peak } \\
\text { wavelength } \\
\text { shift }(\mu \mathrm{m})\end{array}$ & $\begin{array}{l}\text { Wavelength } \\
\text { Sensitivity } \\
(\mathrm{nm} / \mathrm{RIU})\end{array}$ & $\begin{array}{l}\text { Wavelength } \\
\text { Resolution } \\
\text { (RIU) }\end{array}$ \\
\hline 1.33 & 0.63 & 1.47 & 0.01 & 1000 & $1.0 \mathrm{E}-04$ \\
\hline 1.34 & 0.64 & 1.79 & 0.02 & 2000 & $5.0 \mathrm{E}-05$ \\
\hline 1.35 & 0.66 & 1.9 & 0.03 & 3000 & $3.3 \mathrm{E}-05$ \\
\hline 1.36 & 0.69 & 3.07 & 0.05 & 4000 & $2.5 \mathrm{E}-05$ \\
\hline 1.37 & 0.74 & 3.47 & 0.1 & 10000 & $1.0 \mathrm{E}-05$ \\
\hline 1.38 & 0.84 & 5.78 & - & - & - \\
\hline
\end{tabular}

While comparing both the performances of designed tri-path sensor with gold/PtSe 2 layer and when $\mathrm{PtSe}_{2}$ coating layer is removed, we can conclude from the investigation done that the sensing performance is highly enhanced while 2D material $\mathrm{PtSe}_{2}$ is added. While gold/PtSe $\mathrm{P}_{2}$ layer is glazed, the sensitivity reaches much higher sensitivity of $42,000 \mathrm{~nm} / \mathrm{RIU}$. Further, there is also a shift that takes place towards larger wavelength with gold/PtSe ${ }_{2}$ coating layer. The entire wavelength spectrum for gold/PtSe $e_{2}$ layer coating ranges from $0.72 \mu \mathrm{m}$ to $1.38 \mu \mathrm{m}$ which aids the sensor to operate in mid infrared frequency owing to its inter-band transition. The wavelength spectrum range when $\mathrm{PtSe}_{2}$ coating layer is eliminated for the designed tri-path sensor occurs from $0.63 \mu \mathrm{m}$ to $0.84 \mu \mathrm{m}$ respectively. Table 3 is displayed below which gives a ephemeral comparitive study about previously done research works with various materials used for additional coating layer along with our designed tri-path sensor which is intergrated with $\mathrm{PtSe}_{2}$ material through plasmonic gold. From this study analysis, we can conclude that the designed tri-path sensor reaches maximum sensitivity along with low loss which makes it to be anticipated as a budding applicant in various sensing domains.

Table 3: Comparitive study of previously reported research works with different materials for additional coating layer with designed tri-path sensor intergrated with $\mathrm{PtSe}_{2}$ through plasmonic gold. 


\begin{tabular}{|c|c|c|c|c|}
\hline Structure Types & $\begin{array}{l}\text { Range } \\
\text { of RI }\end{array}$ & $\begin{array}{l}\text { Loss } \\
(\mathrm{dB} / \mathrm{cm})\end{array}$ & $\begin{array}{l}\text { Wavelength } \\
\text { Sensitivity } \\
\text { (nm/RIU) }\end{array}$ & $\begin{array}{l}\text { Wavelength } \\
\text { Resolution } \\
\text { (RIU) }\end{array}$ \\
\hline $\begin{array}{l}\text { D-shape PCF with gold/MoS } 2 \text { /graphene } \\
\text { (Singh et al., 2020) }\end{array}$ & $\begin{array}{l}1.33- \\
1.40\end{array}$ & 913.34 & $14,993.34$ & $6.69 \times 10^{-6}$ \\
\hline $\begin{array}{l}\text { Dual core PCF with gold/Tio2 } \\
\text { (Al Mahfuz et al., 2020) }\end{array}$ & $\begin{array}{l}1.33- \\
1.42\end{array}$ & 74.6 & 28,000 & $3.57 \times 10^{-6}$ \\
\hline $\begin{array}{l}\text { Four channel PCF with gold /Tio2 (Islam et } \\
\text { al., 2019) }\end{array}$ & $\begin{array}{l}1.33- \\
1.38\end{array}$ & 50.4 & 25,000 & $4 \times 10^{-6}$ \\
\hline $\begin{array}{l}\text { PCF with gold /2D graphene } \\
\text { (Lou et al., 2019) }\end{array}$ & $\begin{array}{l}1.33- \\
1.38\end{array}$ & 184.53 & 8600 & $\mathrm{~N} / \mathrm{A}$ \\
\hline $\begin{array}{l}\text { Two open channels PCF with silver/gold ( } \\
\text { Liu et al., 2020) }\end{array}$ & $\begin{array}{l}1.22- \\
1.36\end{array}$ & 165.40 & 9000 & $8.06 \times 10^{-6}$ \\
\hline $\begin{array}{l}\text { Tri-path sensor with gold/PtSe } \\
\text { [ proposed work] }\end{array}$ & $\begin{array}{l}1.33- \\
1.38\end{array}$ & 15.82 & 42,000 & $2.4 \times 10^{-6}$ \\
\hline
\end{tabular}

\section{Conclusion}

We propose a tri-path PCF intergrated with SPR sensor along with gold/PtSe ${ }_{2}$ coating layer. The sensor is simple in design where tri-path is formed to make the light pass through the cladding in the scaled down path and interact with the plasmonic surface which produces enhanced coupling effect. FEM is employed for analyzing the sensing performance and numerical simulation investigation for the deisgned tri-path sensor. Gold/PtSe ${ }_{2}$ coating layer for the designed tri-path sensor reveals superior sensing performance when compared with removal of $\mathrm{PtSe}_{2}$ coating layer. They are externally coated over the PCF which makes the sensor economical and reduces the difficulties faced by fabrication. The proposed sensor shows an excessive rise in wavelength sensitivity as $42,000 \mathrm{~nm} / \mathrm{RIU}$ with maximum resolution of $2.4 \mathrm{x}$ $10^{-6} \mathrm{RIU}$ in range of RI analyte 1.33 to 1.38 . Further, when study was done where $\mathrm{PtSe}_{2}$ layer coating was removed, the sensor attains sensitivity of $11,000 \mathrm{~nm} / \mathrm{RIU}$ along with resolution of $1 \times 10^{-5} \mathrm{RIU}$. The simple designed tri-path sensor also achieves low loss which makes it highly applicable and potential candidate 


\section{Declarations}

Funding : No funding was received to assist with the preparation of this manuscript.

Conflicts of interest/Competing interests : The authors have no conflicts of interest to declare that are relevant to the content of this article.

Availability of data and material : Not applicable

Code availability : Not applicable

\section{Authors' contributions :}

1. Vijayalakshmi, C.T.Manimegalai and N. Ayyanar have involved for optimization of proposed work, simulation results analysis, and writing manuscript.

2. Truong Khang Nguyen and Kalimuthu have involved for Result evaluation and Supervision.

Ethics approval : Not applicable

Consent to participate : Not applicable

Consent for publication : Not applicable

\section{References}

Akowuah, E. K., Gorman, T., Ademgil, H., Haxha, S., Robinson, G. K., \& Oliver, J. V.: Numerical analysis of a photonic crystal fiber for biosensing applications. IEEE Journal of Quantum Electronics, 48(11), 14031410 (2012). doi: 10.1109/JQE.2012.2213803.

AlaguVibisha, G., Nayak, J.K., Maheswari, P., Priyadharsini, N., Nisha, A., Jaroszewicz, Z., Rajesh, K.B., Jha, R.: Sensitivity enhancement of surface plasmon resonance sensor using hybrid configuration of 2D materials over bimetallic layer of $\mathrm{Cu}-\mathrm{Ni}$. Opt. Commun. 463, 125337 (2020).

https://doi.org/10.1016/j.optcom.2020.125337

Armelao, L., Barreca, D., Bottaro, G., Bruno, G., Gasparotto, A., Losurdo, M., Tondello, E.: RF-sputtering of gold on silica surfaces: Evolution from clusters to continuous films. Mater. Sci. Eng. C. 25, 599-603 (2005). https://doi.org/10.1016/j.msec.2005.06.007

Ayyanar, N., Khalil, A.E., Hameed, M.F.O., Thavasi Raja, G., Obayya, S.S.A.: Enhanced sensitivity of hemoglobin sensor using dual-core photonic crystal fiber. Opt. Quantum Electron. 50, 1-9 (2018). https://doi.org/10.1007/s11082-018-1710-y

Barnes, M. C., Kim, D. Y., Ahn, H. S., Lee, C. O., \& Hwang, N. M.: Deposition mechanism of gold by thermal evaporation: approach bv charaed cluster model. Journal of crystal growth, 213(1-2), 83-92 (2000). doi: Loading [MathJax]/jax/output/CommonHTML/fonts/TeX/fontdata.js 
Chakma, S., Khalek, M.A., Paul, B.K., Ahmed, K., Hasan, M.R., Bahar, A.N.: Gold-coated photonic crystal fiber biosensor based on surface plasmon resonance: Design and analysis. Sens. Bio-Sensing Res. 18, 712 (2018). https://doi.org/10.1016/j.sbsr.2018.02.003

Gong, Y., Lin, Z., Chen, Y. X., Khan, Q., Wang, C., Zhang, B., ... \& Li, D.: Two-Dimensional Platinum Diselenide: Synthesis, Emerging Applications, and Future Challenges. Nano-Micro Letters, 12(1), 1-34 (2020). doi: 10.1007/s40820-020-00515-0.

Guo, Y., Singh, N.M., Das, C.M., Ouyang, Q., Kang, L., Li, K., Coquet, P., Yong, K.T.: Two-dimensional PtSe2 Theoretically Enhanced Goos-Hänchen Shift Sensitive Plasmonic Biosensors. Plasmonics. 15, 18151826 (2020). https://doi.org/10.1007/s11468-020-01204-9

Haider, F., Aoni, R.A., Ahmed, R., Islam, M.S., Miroshnichenko, A.E.: Propagation Controlled Photonic Crystal Fiber-Based Plasmonic Sensor via Scaled-Down Approach. IEEE Sens. J. 19, 962-969 (2019). https://doi.org/10.1109/JSEN.2018.2880161

Hasan, M.R., Akter, S., Ahmed, K., Abbott, D.: Plasmonic Refractive Index Sensor Employing Niobium Nanofilm on Photonic Crystal Fiber. IEEE Photonics Technol. Lett. 30, 315-318 (2018)(a). https://doi.org/10.1109/LPT.2017.2786475

Hasan, M.R., Akter, S., Rifat, A.A., Rana, S., Ahmed, K., Ahmed, R., Subbaraman, H., Abbott, D.: Spiral photonic crystal fiber-based dual-polarized surface plasmon resonance biosensor. IEEE Sens. J. 18, 133140 (2018)(b). https://doi.org/10.1109/JSEN.2017.2769720

Huang, T.: Highly Sensitive SPR Sensor Based on D-shaped Photonic Crystal Fiber Coated with Indium Tin Oxide at Near-Infrared Wavelength. Plasmonics. 12, 1-6 (2017). https://doi.org/10.1007/s11468-0160301-7

Islam, M.S., Cordeiro, C.M.B., Sultana, J., Aoni, R.A., Feng, S., Ahmed, R., Dorraki, M., Dinovitser, A., Ng, B.W.H., Abbott, D.: A Hi-Bi Ultra-Sensitive Surface Plasmon Resonance Fiber Sensor. IEEE Access. 7, 79085-79094 (2019). https://doi.org/10.1109/ACCESS.2019.2922663

Jabin, M.A., Ahmed, K., Rana, M.J., Paul, B.K., Islam, M., Vigneswaran, D., Uddin, M.S.: Surface Plasmon Resonance Based Titanium Coated Biosensor for Cancer Cell Detection. IEEE Photonics J. 11, 1-10 (2019). https://doi.org/10.1109/JPHOT.2019.2924825

Jia, Y., Li, Z., Wang, H., Saeed, M., Cai, H.: Sensitivity enhancement of a surface plasmon resonance sensor with platinum diselenide. Sensors (Switzerland). 20, (2020). https://doi.org/10.3390/s20010131

Kaur, V., Singh, S.: Design of titanium nitride coated PCF-SPR sensor for liquid sensing applications. Opt. Fiber Technol. 48, 159-164 (2019). https://doi.org/10.1016/j.yofte.2018.12.015 
Liu, C., Wang, J., Jin, X., Wang, F., Yang, L., Lv, J., ... \& Chu, P. K.: Near-infrared surface plasmon resonance sensor based on photonic crystal fiber with big open rings. Optik, 207, 164466 (2020). doi:

$10.1016 /$ j.jileo.2020.164466.

Lou, J., Cheng, T., Li, S., Zhang, X.: Surface plasmon resonance photonic crystal fiber biosensor based on gold-graphene layers. Opt. Fiber Technol. 50, 206-211 (2019).

https://doi.org/10.1016/j.yofte.2019.03.028

Luan, N., Yao, J.: Refractive Index and Temperature Sensing Based on Surface Plasmon Resonance and Directional Resonance Coupling in a PCF. IEEE Photonics J. 9, 1-5 (2017).

https://doi.org/10.1109/JPHOT.2017.2667878

Al Mahfuz, M., Hossain, M.A., Haque, E., Hai, N.H., Namihira, Y., Ahmed, F.: A bimetallic-coated, low propagation loss, photonic crystal fiber based plasmonic refractive index sensor. Sensors (Switzerland). 19, (2019). https://doi.org/10.3390/s19173794

Mahfuz, M. Al, Hossain, M.A., Haque, E., Hai, N.H., Namihira, Y., Ahmed, F.: Dual-Core Photonic Crystal Fiber-Based Plasmonic RI Sensor in the Visible to Near-IR Operating Band. IEEE Sens. J. 20, 7692-7700 (2020). https://doi.org/10.1109/JSEN.2020.2980327

Nivedha, S., Ramesh Babu, P., Senthilnathan, K.: D-shaped plasmonic sensor using a molybdenum disulfide doped photonic crystal fiber. IOP Conf. Ser. Mater. Sci. Eng. 263, 3-7 (2017). https://doi.org/10.1088/1757-899X/263/5/052031

Otupiri, R., Akowuah, E.K., Haxha, S.: Multi-channel SPR biosensor based on PCF for multi-analyte sensing applications. Opt. Express. 23, 15716 (2015). https://doi.org/10.1364/oe.23.015716

Ouyang, Q., Zeng, S., Jiang, L., Hong, L., Xu, G., Dinh, X.Q., Qian, J., He, S., Qu, J., Coquet, P., Yong, K.T.: Sensitivity Enhancement of Transition Metal Dichalcogenides/Silicon Nanostructure-based Surface Plasmon Resonance Biosensor. Sci. Rep. 6, 1-13 (2016). https://doi.org/10.1038/srep28190

Qin, W., Li, S.G., Xue, J.R., Xin, X.J., Zhang, L.: Numerical analysis of a photonic crystal fiber based on two polarized modes for biosensing applications. Chinese Phys. B. 22, 2-8 (2013).

https://doi.org/10.1088/1674-1056/22/7/074213

Radisavljevic, B., Radenovic, A., Brivio, J., Giacometti, V., Kis, A.: Single-layer MoS2 transistors. Nat. Nanotechnol. 6, 147-150 (2011). https://doi.org/10.1038/nnano.2010.279

Rahman, M.M., Rana, M.M., Rahman, M.S., Anower, M.S., Mollah, M.A., Paul, A.K.: Sensitivity enhancement of SPR biosensors employing heterostructure of PtSe2 and 2D materials. Opt. Mater. (Amst). 107, 110123 (2020). https://doi.org/10.1016/j.optmat.2020.110123

Sazio, P.J.A., Amezcua-Correa, A., Finlayson, C.E., Hayes, J.R., Scheidemantel, T.J., Baril, N.F., Jackson, Loading [MathJax]/jax/output/CommonHTML/fonts/TeX/fontdata.js i, V.H., Badding, J. V.: Microstructured optical 
fibers as high-pressure microfluidic reactors. Science (80-. ). 311, 1583-1586 (2006). https://doi.org/10.1126/science.1124281

Singh, S., Prajapati, Y.K.: Dual-polarized ultrahigh sensitive gold/MoS2/graphene based D-shaped PCF refractive index sensor in visible to near-IR region. Opt. Quantum Electron. 52, (2020). https://doi.org/10.1007/s11082-019-2122-3

Sioss, J.A., Keating, C.D.: Batch preparation of linear Au and Ag nanoparticle chains via wet chemistry. Nano Lett. 5, 1779-1783 (2005). https://doi.org/10.1021/nl051370u

Vial, A., Grimault, A.S., Macías, D., Barchiesi, D., Lamy De La Chapelle, M.: Improved analytical fit of gold dispersion: Application to the modeling of extinction spectra with a finite-difference time-domain method. Phys. Rev. B - Condens. Matter Mater. Phys. 71, 1-7 (2005).

https://doi.org/10.1103/PhysRevB.71.085416

Vigneswaran, D., Ayyanar, N., Sharma, M., Sumathi, M., Mani, M.R., Porsezian, K.: Salinity sensor using photonic crystal fiber. Sensors Actuators, A Phys. 269, 22-28 (2018).

https://doi.org/10.1016/j.sna.2017.10.052

Wang, Y., Wang, D.N., Yang, F., Li, Z., Yang, M.: Sensitive hydrogen sensor based on selectively infiltrated photonic crystal fiber with Pt-loaded WO_3 coating. Opt. Lett. 39, 3872 (2014).

https://doi.org/10.1364/ol.39.003872

Wu, L., Jia, Y., Jiang, L., Guo, J., Dai, X., Xiang, Y., Fan, D.: Sensitivity Improved SPR Biosensor Based on the MoS2/Graphene-Aluminum Hybrid Structure. J. Light. Technol. 35, 82-87 (2017).

https://doi.org/10.1109/JLT.2016.2624982

Xie, J., Zhang, D., Yan, X. Q., Ren, M., Zhao, X., Liu, F., ... \& Tian, J. G.: Optical properties of chemical vapor deposition-grown PtSe2 characterized by spectroscopic ellipsometry. 2D Materials, 6(3), 035011 (2019). doi:10.1088/2053-1583/ab1490.

Zhang, X., Teng, S.Y., Loy, A.C.M., How, B.S., Leong, W.D., Tao, X.: Transition metal dichalcogenides for the application of pollution reduction: A review. Nanomaterials. 10, (2020).

https://doi.org/10.3390/nano10061012

Zhang, Y.N., Wu, Q., Peng, H., Zhao, Y.: Photonic crystal fiber modal interferometer with Pd/WO3 coating for real-time monitoring of dissolved hydrogen concentration in transformer oil. Rev. Sci. Instrum. 87, (2016). https://doi.org/10.1063/1.4971321

\section{Figures}




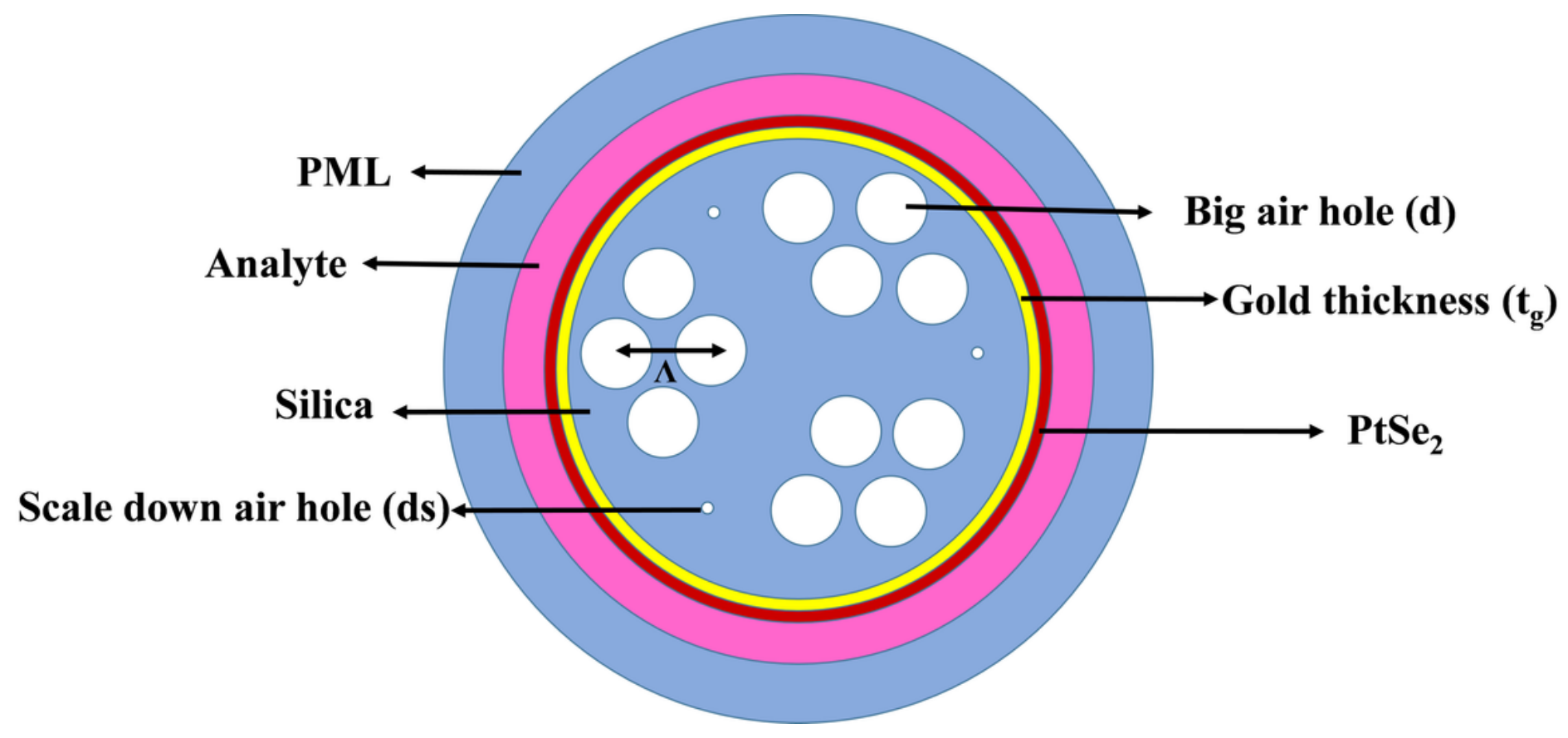

Figure 1

Schematic 2D view of designed tri-path PCF-SPR sensor with gold/PtSe2 coating layer
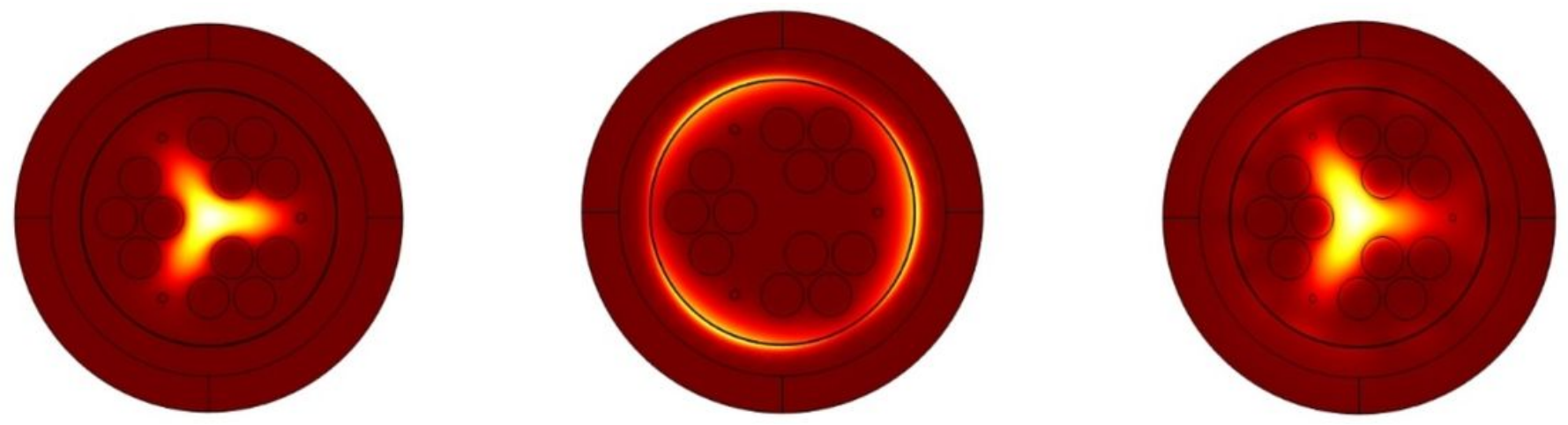

Figure 2

Field distribution of analyte 1.36 (a) fundamental core mode (b) plasmonic mode (c) coupling effect at $0.84 \mu \mathrm{m}$ 


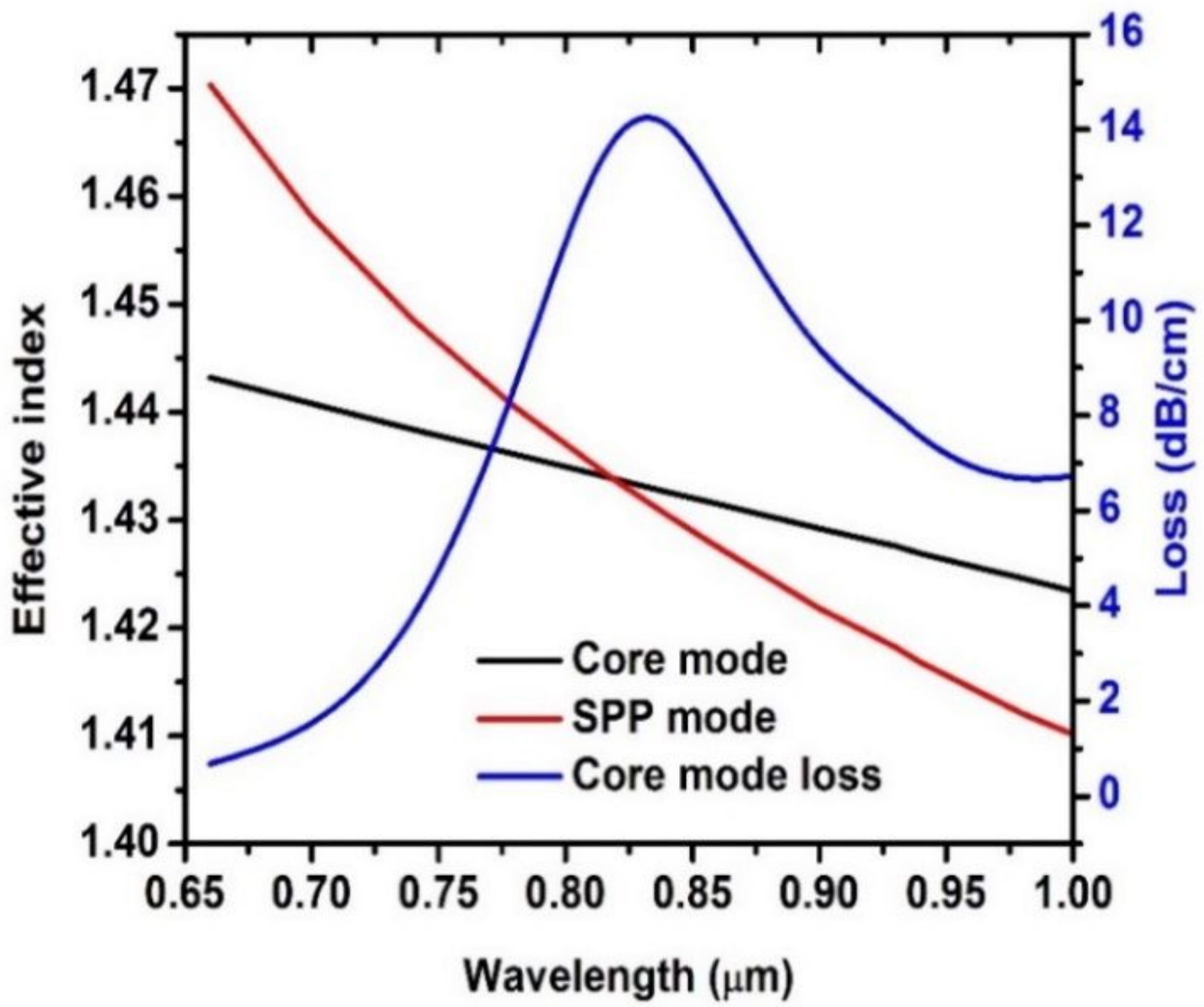

Figure 3

Dispersion relation represented for core mode, plasmonic mode and loss spectrum of fundamental core mode for analyte RI 1.36 


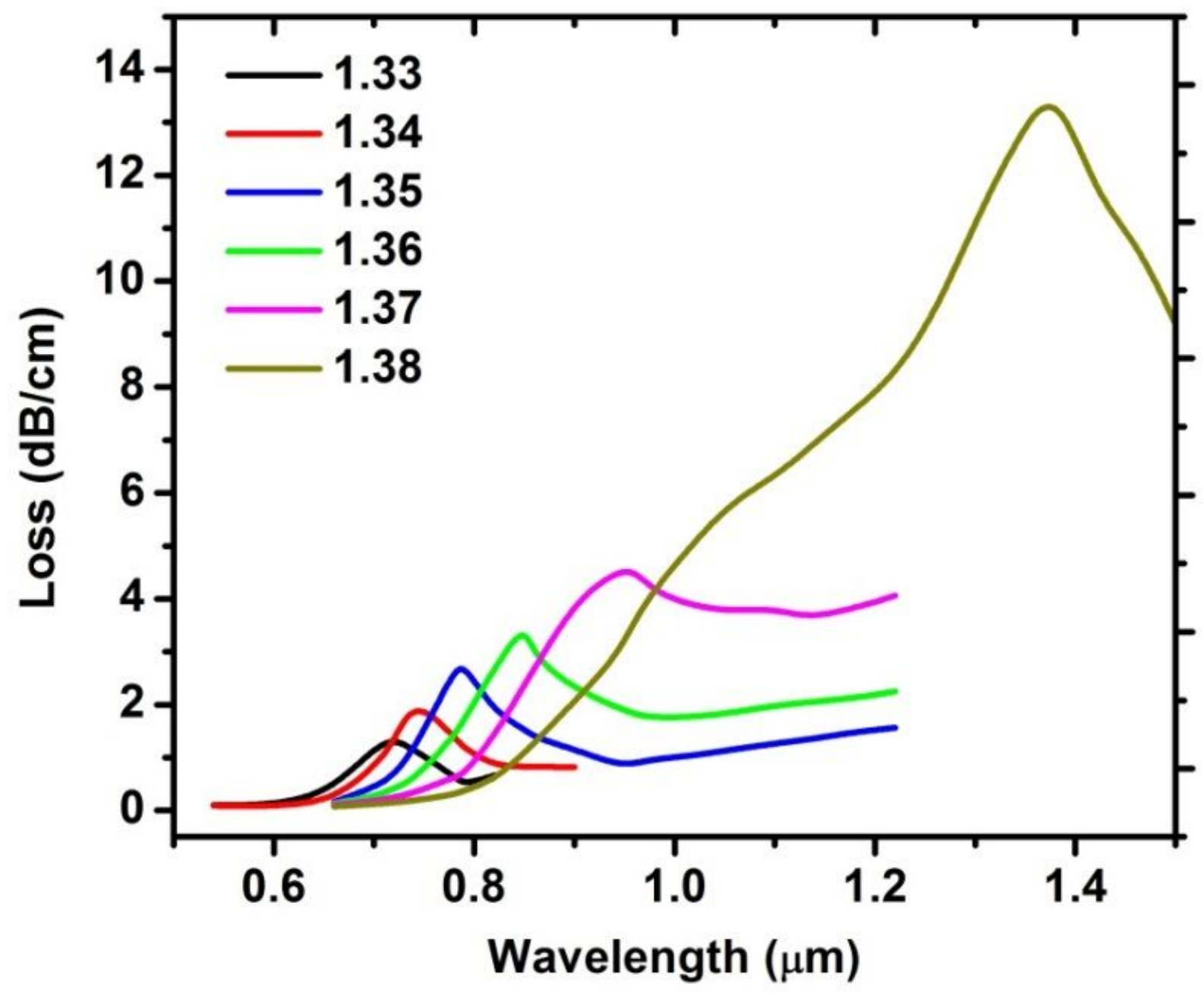

Figure 4

Loss spectrum for analyte RI varied from 1.33 to 1.38 with gold/PtSe2 coating layer 


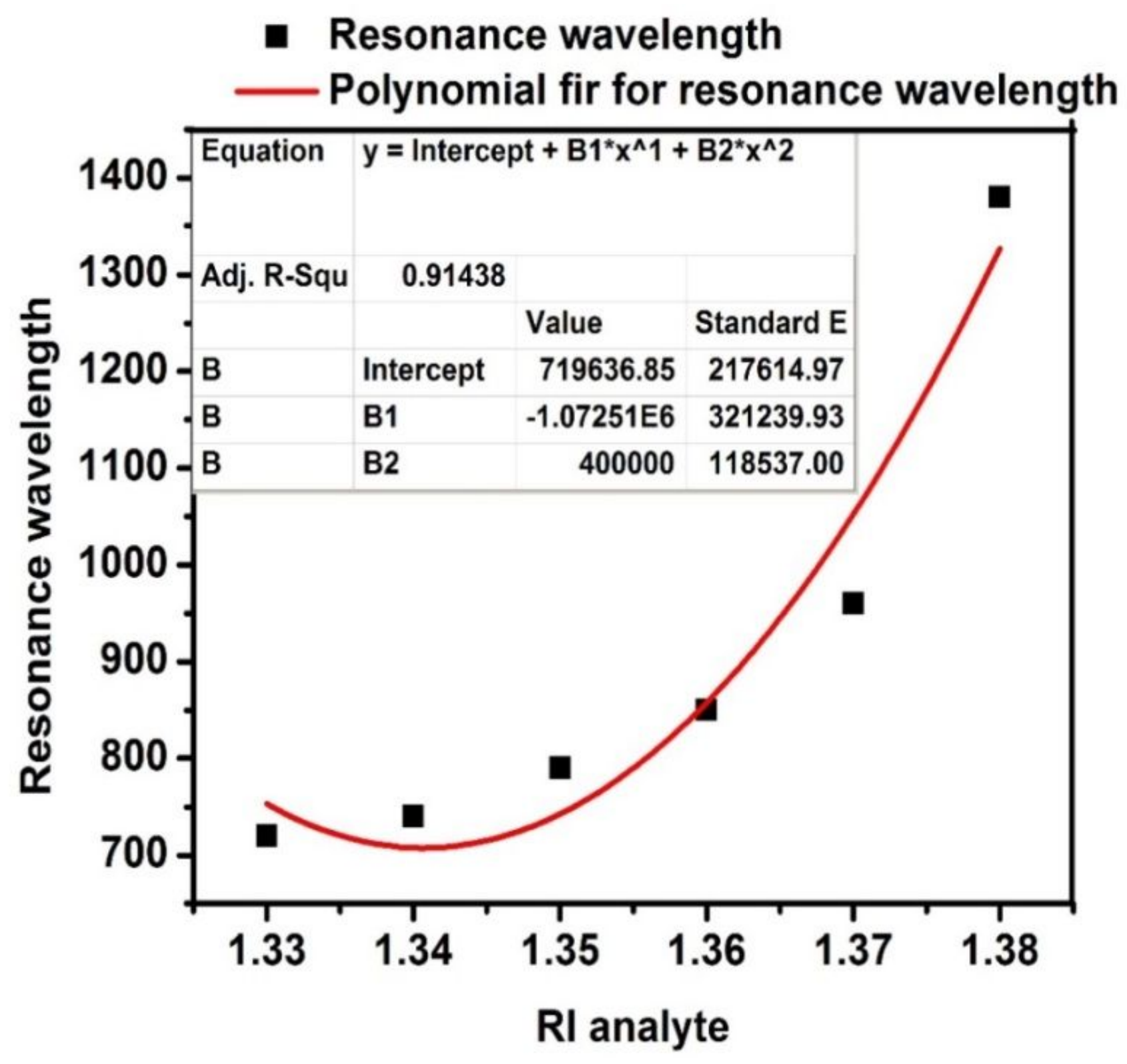

Figure 5

Polynomial fit curve analysis for analyte RI altered from 1.33 to 1.38 with gold/PtSe2 coating layer 


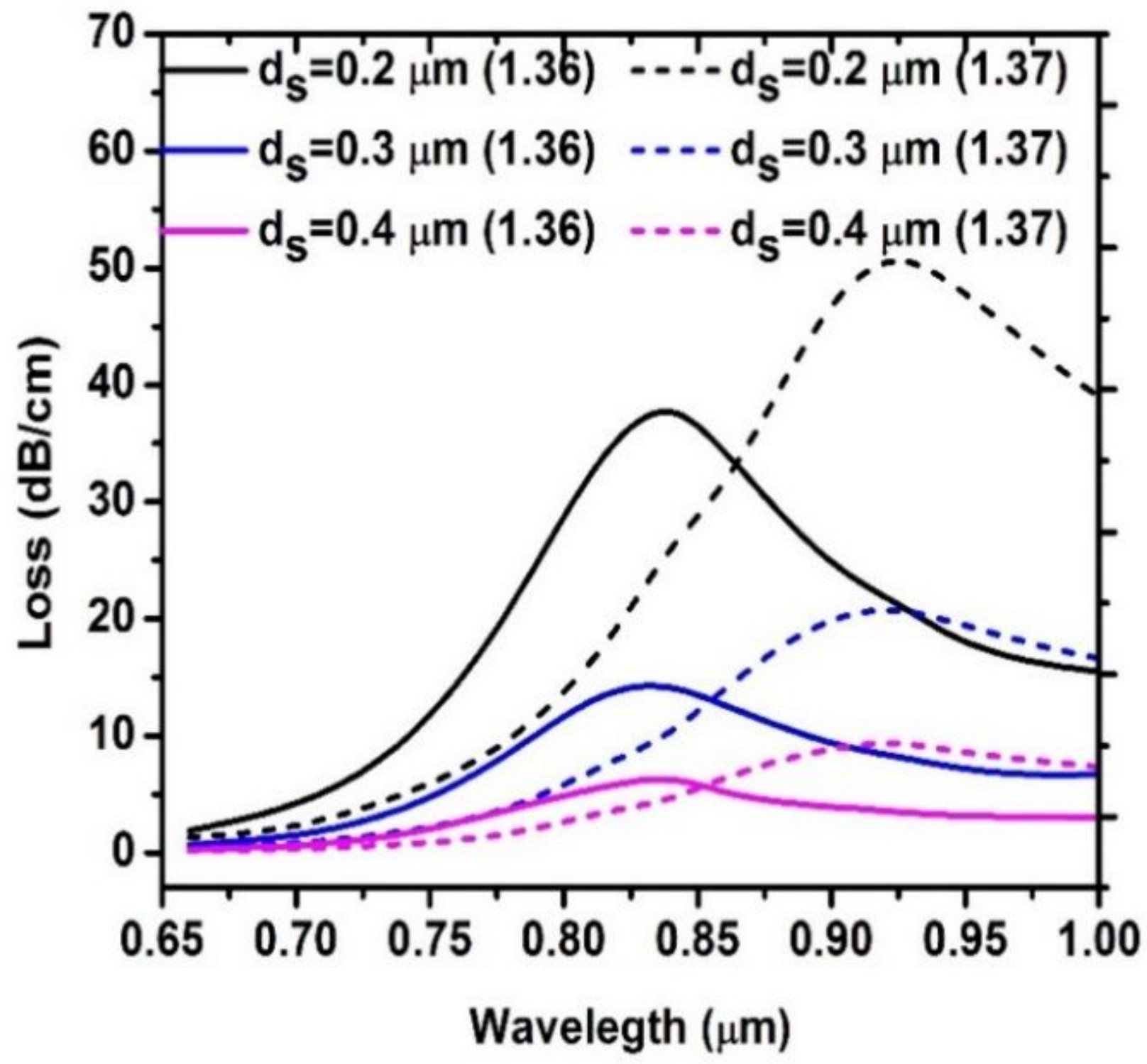

Figure 6

Polynomial fit curve analysis for analyte RI altered from 1.33 to 1.38 with gold/PtSe2 coating layer 


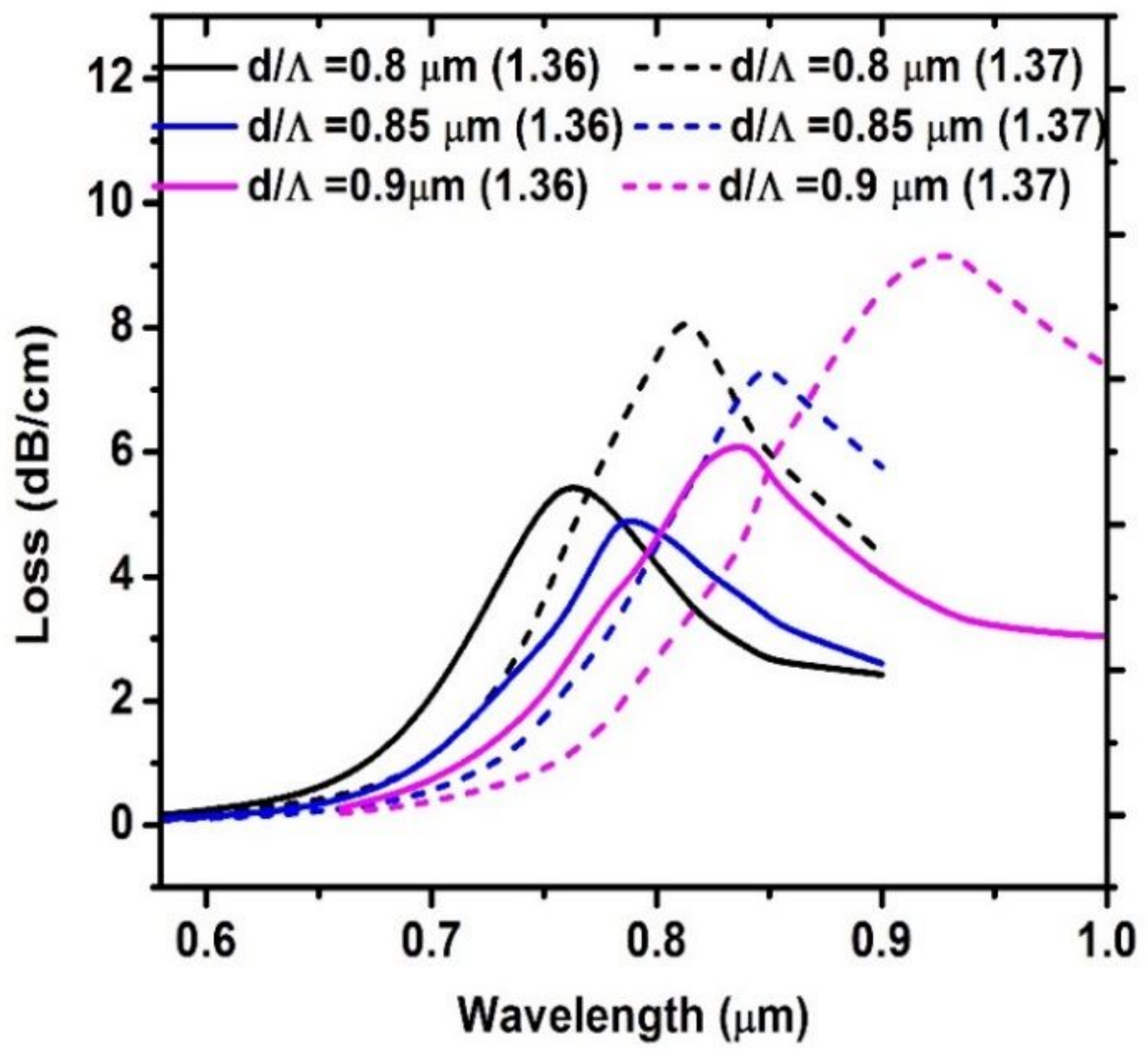

Figure 7

Loss peak of ratio amongst diameter of big airhole and pitch, dp which is modified from $0.8 \mu \mathrm{m}$ to $0.9 \mu \mathrm{m}$ 


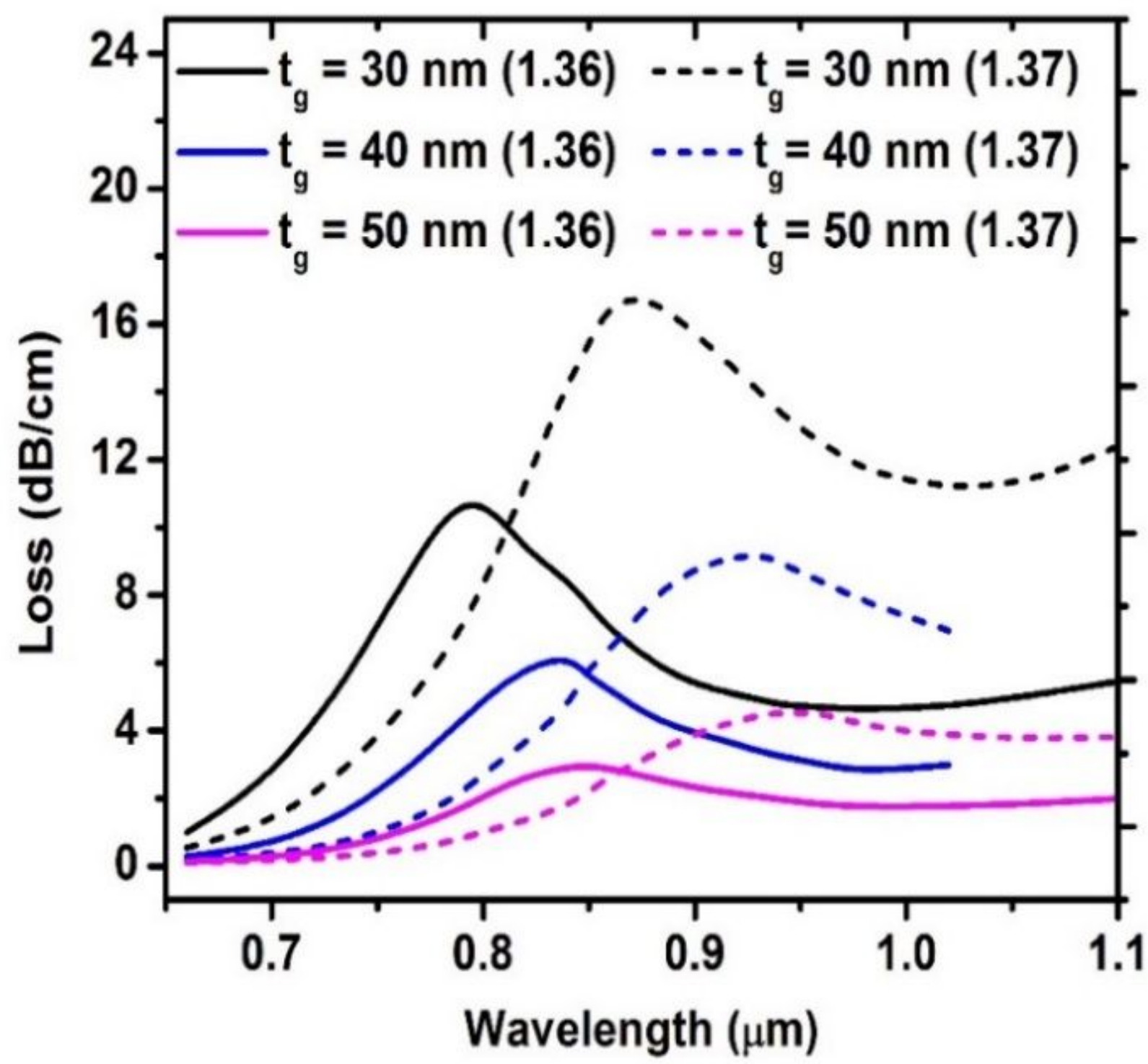

Figure 8

Loss peak of gold thickess variation from $30 \mathrm{~nm}$ to $50 \mathrm{~nm}$ 


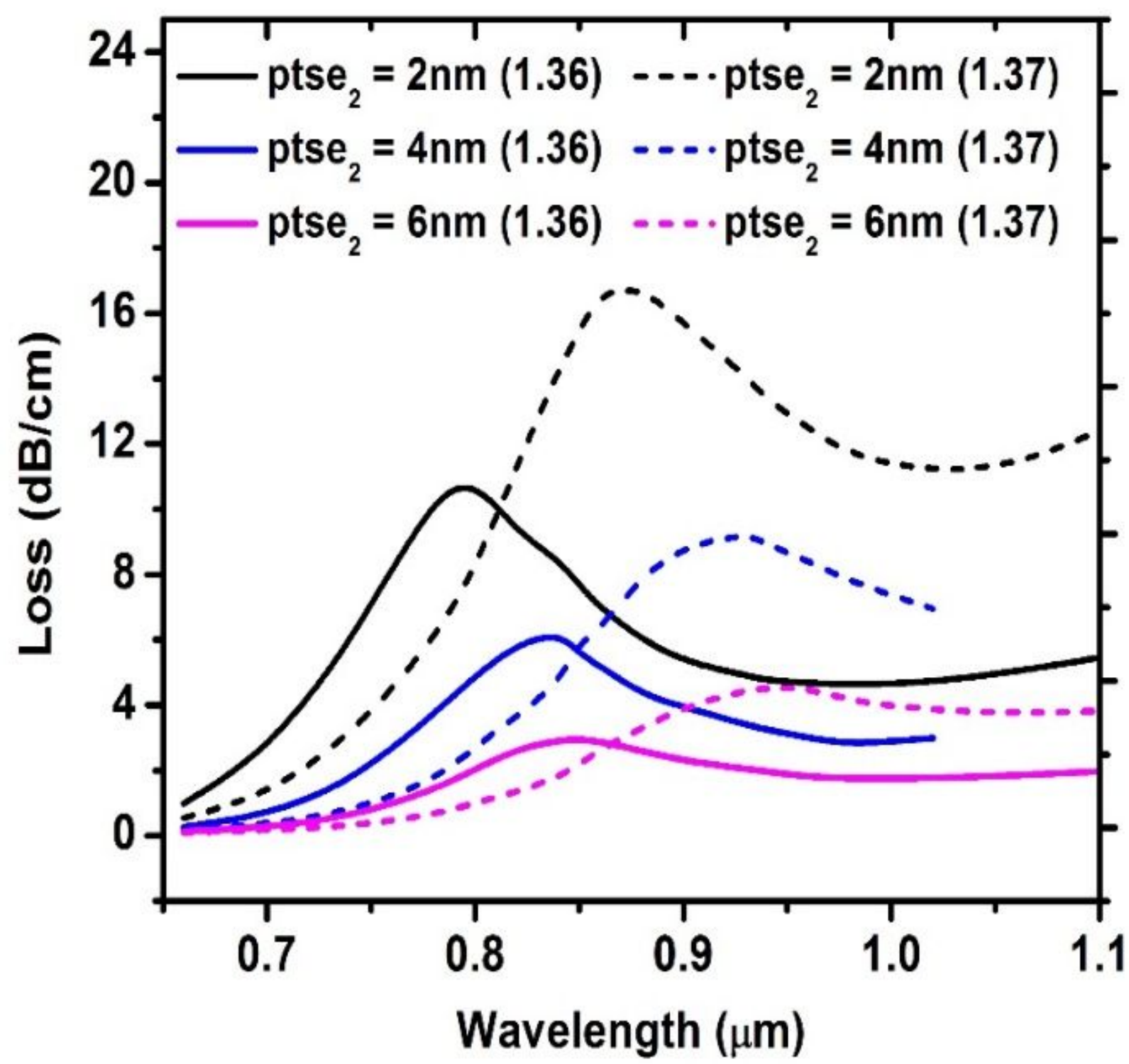

Figure 9

Loss spectrum for the thickness of PtSe2 amended from $2 \mathrm{~nm}$ to $4 \mathrm{~nm}$ 


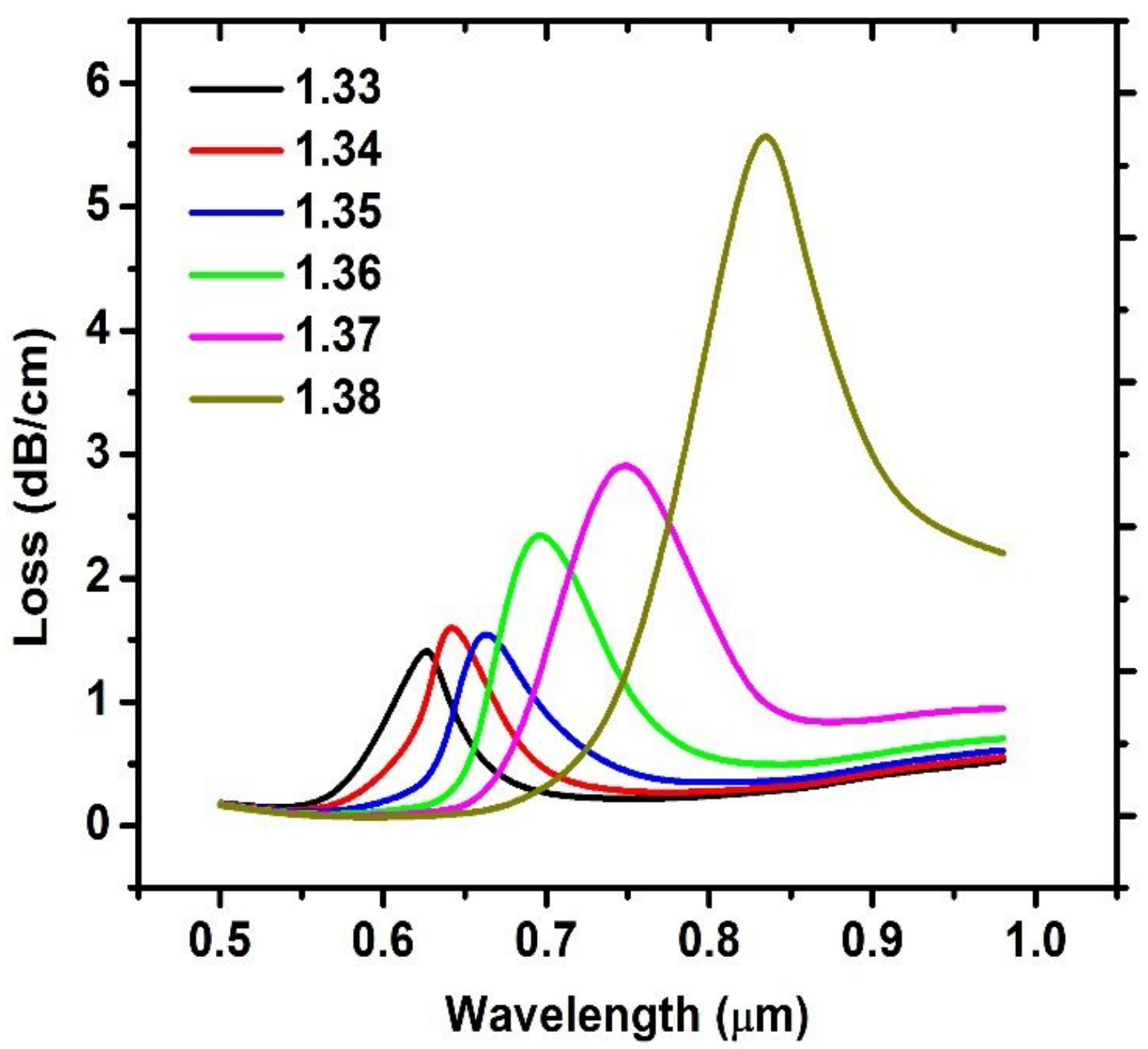

Figure 10

Loss spectrum for analyte RI varied from 1.33 to 1.38 with no PtSe2 material coating 
- Resonance wavelength

- Polynomial fit for resonance wavelength

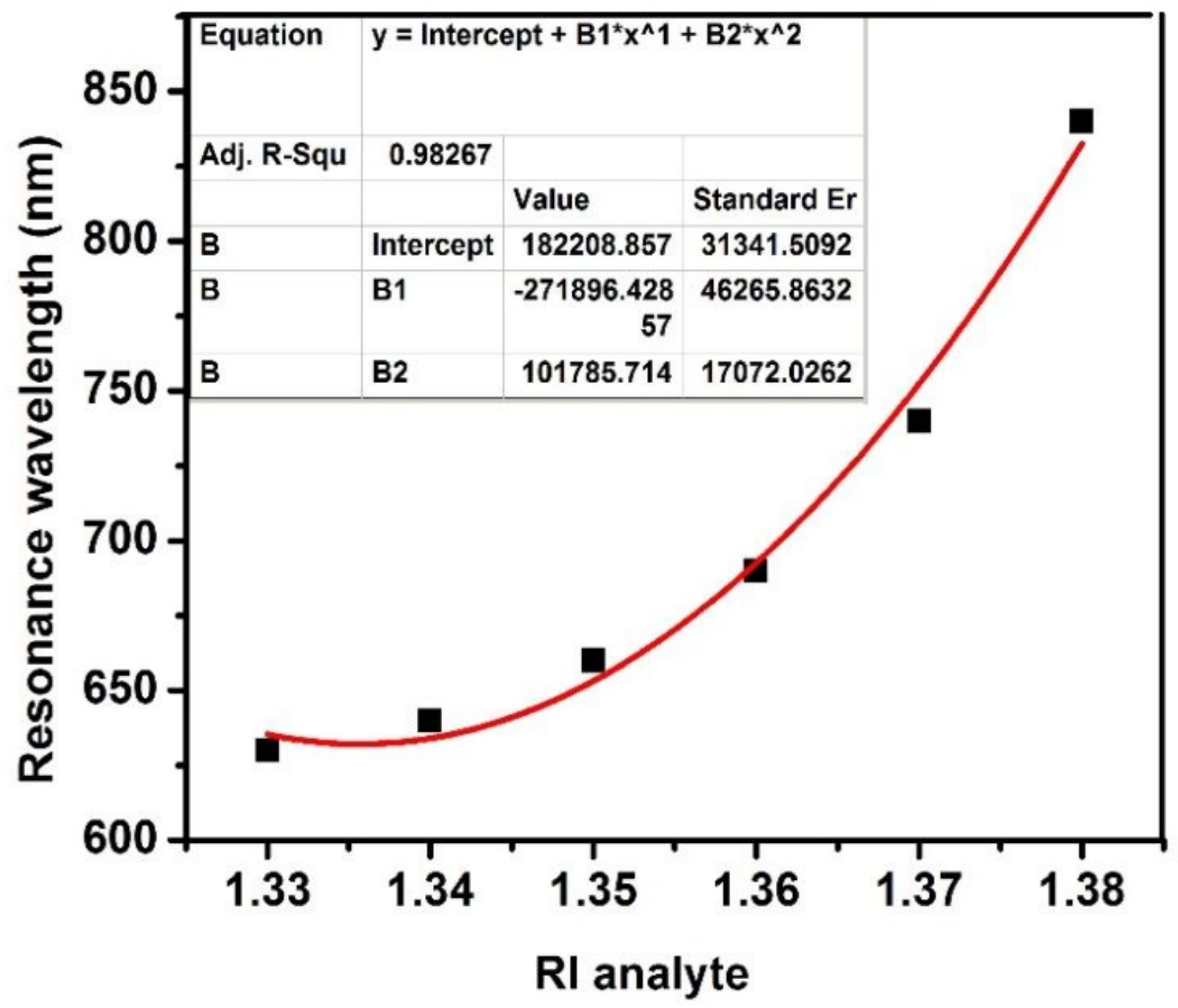

Figure 11

Polynomial fit curve analysis for analyte RI altered from 1.33 to 1.38 with no PtSe2 layer coating 